\title{
Auf der Zielgeraden
}

Die Formnext steht vor der Tür und schon jetzt ist klar: Die Zeit der Prototypenentwicklung ist auch bei den additiven Fertigungstechnologien für Keramik nun vorbei. Die Verfahren sind den Kinderschuhen entwachsen und das nächste große Ziel ist fast in Reichweite. Der Traum vieler, die sich in den letzten Jahren der Entwicklung von Druckern, Materialien und Prozessen für die additive Fertigung von Keramik verschrieben haben, könnte bald Realität werden. Die Technologie ist einen weiten Weg gegangen von der Grundlagenforschung bis zu einer Markteinführung. Die Bauteile wurden filigraner, die Gestaltungsmöglichkeiten vielfältiger, und mittlerweile halten additiv gefertigte Keramiken mit den Eigenschaften konventionell gefertigter Bauteile ohne Probleme mit. Damit sind 3D-Drucker nicht nur ein nützliches Werkzeug in der Forschung, sondern können ebenso in der Industrie für die
Serienfertigung eingesetzt werden. Auch der Multimaterialdruck, die Kombination von mehreren Materialien wie zum Beispiel verschiedenen Keramiken oder Keramik und Metall sowie Polymer, ist heute möglich und eröffnet neue Designoptionen von multifunktionellen Bauteilen, die verschiedene Materialeigenschaften in sich vereinen können.

War am Anfang vor allem der Pioniergeist der Entwickler ein treibender Faktor für den zukünftigen Erfolg der additiven Fertigung von Keramik, sind nun die Unternehmen an der Reihe, die nötigen Schritte zu gehen. In der Produktion sind neue Strukturen und Konzepte zu etablieren und es muss ein Verständnis für die neue Designfreiheit geschaffen werden, die dieses Formgebungsverfahren mit sich bringt. So lässt sich die nächste Stufe auf dem Weg zu einem Fertigungsverfahren für die industrielle Serienproduktion erreichen.

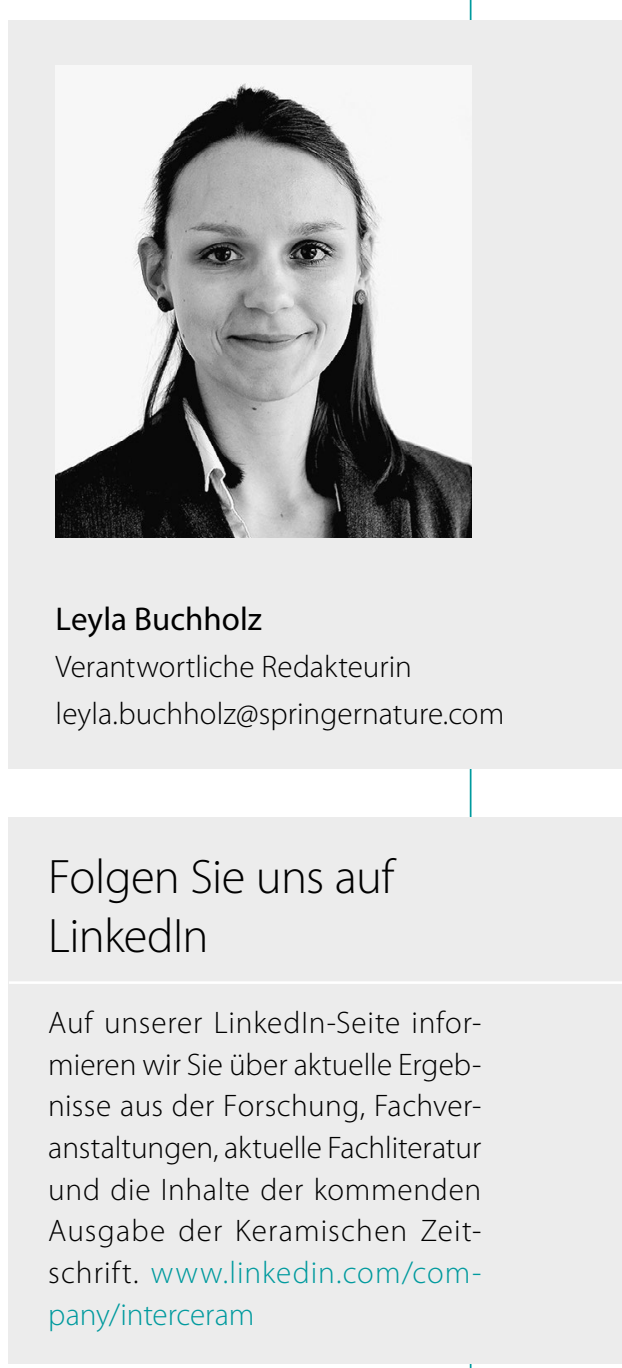

